\title{
THE ORIGIN AND EVOLUTION OF THE HUMAN DENTITION
}

Quotations from the Preface of the Author's Book on This Subject, Recently Published for the Journal of Dental Research ${ }^{1}$

WILLIAM K. GREGORY

Columbia University, and the American Museum of Natural History, New York City

The facts and interpretations of facts in the author's book are such as have presented themselves during the course of the author's palæontological studies at Columbia University and at the American Museum of Natural History, where since 1900 the author has had the inestimable privilege of close association with Professor Henry Fairfield Osborn.

As fully set forth in Professor Osborn's work on the Evolution of Mammalian Molar Teeth (1907), we owe to the late Professor E. D. Cope of Philadelphia the discovery (1883) that the "tritubercular type was ancestral to many if not all the higher types of molar teeth." "This," writes Professor Osborn, "is one of the most important generalizations ever made in mammalian comparative anatomy." He further says that in his opinion "the evidence in favor of it is so overwhelming that primitive trituberculy is no longer an hypothesis or a theory but an established fact." Similarly Doctor J. L. Wortman, author of a standard work on the Comparative Anatomy of the Teeth of the Vertebrata (1886), and the discoverer and describer of many important types of Eocene mammals, writes thus of Cope's theory of Trituberculy: ${ }^{2}$

"The broad generalization sought to be established by this theory is one of the most important and far reaching deductions within the whole range of mammalian morphology, and is a performance in every way worthy of

${ }^{1}$ The concluding section $(\mathrm{V})$ of the book referred to was published on pages $87-228$ of this volume (March issue). These quotations from the preface supplement and explain certain features of the comment in the previous publications by Dr. Gregory in this Journal, on "the origin and evolution of the human dentition." (W. J. G.)

${ }^{2}$ Wortman, J. L. Evolution of molar cusps in mammals. American Journal of Physical Anthropology, 1921, iv, pp, 177-188. 
the great master mind that conceived it. It is one of the many enduring monuments that will stand to the credit of this greatest of all American morphologists as long as the science is cultivated.

"It is to be observed that Cope's theory of Trituberculy, as the name implies, sought only to reduce the highly developed and complex molar patterns to the basis of the simple three-cusped stage, and his researches and discoveries were largely to this end. These studies were mostly made upon the Amblypoda, Phenacodonts, Ungulates, Primates, Carnivores and related groups, and it is largely upon the molar evolution of these orders that the generalization rests. In this, Cope's researches have been epochmaking and it was almost wholly through these efforts that the evolution of the complex and complicated molar patterns of these forms was first completely understood. In the further development and elaboration of this subject, the researches of Cope have been powerfully supplemented by the work of Scott and Osborn, especially the latter, who has contributed greatly to our knowledge along these lines."

These statements by Professor Osborn and Doctor Wortman in support of Cope's generalization rest upon the broadest basis of fact. Since 1891 expeditions from the American Museum of Natural History have collected many thousand specimens of fossil mammals from a long and closely graded series of horizons in the Paleocene, Eocene and later formations of the West. These enormous collections, which are still being described in American Museum publications, afford cumulative evidence (which only those who know the material at first hand can fully appreciate) for Cope's and Osborn's conclusion that trigonal upper molars and "tuberculo-sectorial" lower molars are truly ancestral in pattern and may be traced along divergent lines into the more complex molars of various groups of carnivores, condylarths, perissodactyls, primates and other orders. Nor should we forget the reënforcement of this conclusion afforded by the great collections of European fossil mammals, as described during recent years by Depéret, Schlosser, Stehlin and many other palæontologists.

In 1895 Professor Osborn applied to the cusps of the human molars the system of nomenclature which he had invented at an earlier period for the molar patterns of Eocene mammals, replacing such cumbrous terms as anterior palatal, anterior buccal, etc., with the simple and easily remembered terms of protocone, paracone, meta- 
cone, hypocone, for the cusps of the upper molars, ${ }^{3}$ and protoconid, metaconid, hypoconid, entoconid and hypoconulid for those of the lower molars." "When we understand," he continued, "that all the teeth of all mammals have this key, this tritubercular key, we can unlock the comparisons through the series and point out the homologies," a statement which, after certain reservations and restrictions have been made, is still, in the judgment of the writer, essentially true.

Unfortunately the numerous and fundamental contributions of Professors Cope and Osborn to the subject of the evolution of mammalian molar teeth, from the tritubercular type onward, are too often lost sight of as a result of the altogether disproportionate attention that has been devoted to the "Cope-Osborn hypothesis" of the origin of the tritubercular molar from the triconodont molar. ${ }^{5}$ This "frail hypothesis," as the writer has called it (1916, p. 240), was that triangular molars had been derived from the triconodont type with three cusps in fore-and-aft line, by the migration, rotation, or circumduction, of the two marginal cusps, outward in the upper and inward in the lower jaw.

The Cope-Osborn hypothesis has been rejected, as insufficient or in conflict with other evidence, by several authors, including Dr. J. L. Wortman (1903-'04). Professor Osborn in 1907 (p. 8) restated the evidence in its favor and concluded, "there is thus evidence for cusp rotation, but it is not an essential part of the tritubercular theory, because, as above stated, the denticles (para- and metacones) may have arisen on the inner and outer sides of the crown from the outset."

$$
\begin{aligned}
{ }^{3} \text { protocone } & =\text { mesiolingual } \\
\text { paracone } & =\text { mesiobuccal } \\
\text { metacone } & =\text { distobuccal } \\
\text { hypocone } & =\text { distolingual }
\end{aligned}
$$

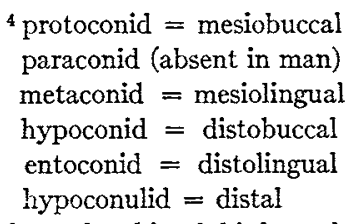

${ }^{5}$ Wortman (loc, cit., p. 187) attributes to Osborn the authorship of this hypothesis; but Cope (in his Origin of the Fittest, p. 347) refers to it as his own, and Osborn has always $(1888$, p. $243 ; 1907$, p. 4) given Cope the credit for it. It is clearly set forth in Cope's article on the Creodonta in the American Naturalist, 1884, p. 259. For full references here and beyond see the corresponding bibliography on page 218 of this volume. 

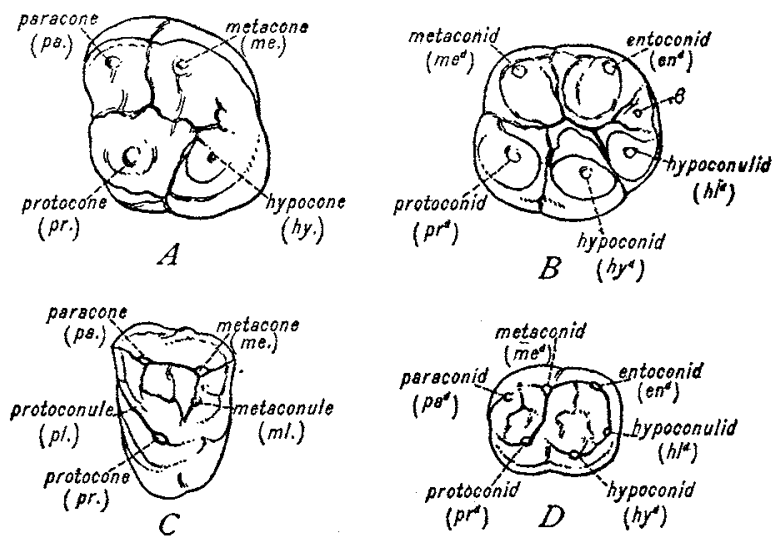

Fig. A. The Osbornian Nomenctature of the Molar Cusps

A.--Second left upper molar of man (Kaffir).

B.-Second left lower molar of man (Australian black).

C.-Second left upper molar of Pelycodus trigonodus, a lower Eocene lemuroid.

D.-Second left lower molar of the same species.

$\mathrm{C}$ and $\mathrm{D}$ represent the primitive, tritubercular upper molar and tuberculo-sectorial lower molar.

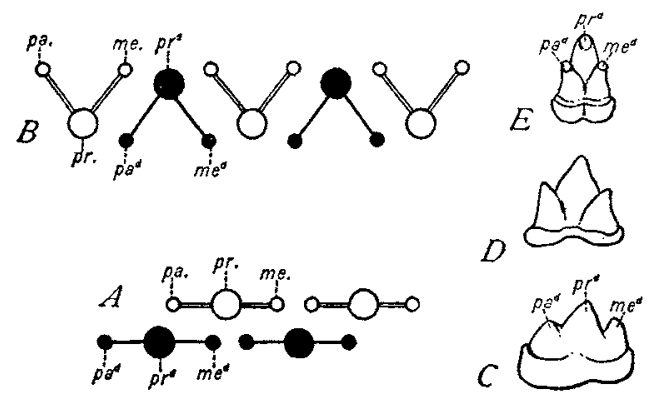

Fig. B. The Cope-Osborn Hypothests of the Ctrcunduction of the Para- and METACONES

A.-Triconodont stage with all three cusps in the same antero-posterior plane, as represented by Amphilestes (C).

B.- Tritubercular stage with the two minor cusps circumducted to the outer side in the upper teeth (white) and to the inner side in the lower (black).

C.-A lower molar of Amphilestes, Jurassic, England.

D.-A lower molar of Menacodon, Jura-Cretaceous, Wyoming. Inner side showing the paraconid and metaconid partly displaced to the inner side of the crown.

E.-A lower molar of Spalacotherium, Jurassic, England. Paraconid and metaconid completely displaced to the inner side of the crown.

This hypothesis is applicable, if at all, only to the origin of the molar patterns of the Triconodonta and not to other orders of mammals. 
In the present work (Part I) as well as in previous ones (1910, p. $193 ; 1916$, p. $242-3$ ), the author supports the view that in the remote ancestors of typical mammals the para- and metaconids of the lower molars probably arose, in situ, as up-growths from the cingulum, but that in Spalacotherium, Menacodon and their allies there may have been a migration or shifting of the para- and metaconids. The view of Cope and Osborn that the so-called protocone (mesio-lingual cusp) of typical upper molars represents the original apex of the crown, has been attacked by many authors, as set forth by Osborn (1907) and the present writer (1916).

Recognizing the cumulative weight of the evidence that in the upper molars of early Tertiary mammals the so-called protocone is not the oldest, or first cusp, but represents an upgrowth from the basal tubercle or cingulum [as maintained especially by Wortman (1903-'04), Gidley (1906), Matthew (1910), Gregory (1916)], and that the primitive tip of the reptilian crown lies in the paracone (or para + metacone), the author has formulated in the present work (Parts I, II, fig. 44) the following principles:

(1) That in the triangular upper molars of early Tertiary mammals there are two principal "trigons," (a) the primary trigon, consisting of the divided "original tip" (para + metacone) and the external cingulum, and (b) the secondary trigon, comprising the inwardly grown "protocone" and the divided original tip.

(2) That the homologue of the trigonid of the lower molars is not the secondary but the primary trigon.

It follows from these principles, and from studies of the occlusal relations of the upper and lower teeth, that Cope's conception of the origin of the tritubercular molar and, consequently, the whole nomenclature of the mammalian molars proposed by Professor Osborn, probably rest upon a misconception, by which the secondary trigon of the upper molar was viewed as corresponding with the primary trigonid of the lower molar.

But are we therefore to agree with Dr. Wortman $(1903,1921)$ and abandon the use of the Osbornian nomenclature? Gidley (1906), Matthew (1910) and the writer (1916) hold that as these names are far more widely used by palæontologists than any others, it is not likely that they will readily give up such a convenient system for 
any of the cumbersome substitutes that have been proposed. Even although the "protocone" of the upper molars is probably not the oldest cusp of the mammalian molar crown, its name need not carry the implication of oldest, if used as a conventional name for that cusp. And even although the protocone of the upper molar has probably arisen with and is functionally analogous with the talonid, or posterior part of the lower molars (see Parts I, II), it would be in the highest degree confusing either to abandon the Osbornian nomenclature at this late date or to try to rectify it in accordance with the newer ideas. Such a compromise will no doubt be unacceptable to rigorous idealists who do not recognize that the terminology in question consists of more or less arbitrarily chosen symbols, which, although not always appropriate, have the merit of being well defined, practicable and in wide use.

For readers who desire to gain a preliminary idea of the contents of this work is suggested, first, an inspection of figs. 346-353 inclusive, ${ }^{6}$ illustrating the stages in the evolution of the human skull and dentition from fish to man, and secondly, a cursory review of the summaries and conclusions at the end of each part. ${ }^{7}$

It will be observed that the author contributes nothing new to the Piltdown problem, but leaves it in statu quo. While Part $\mathrm{V}^{8}$ was in press, and since that time, Professor Osborn, Dr. Matthew and Professor J. H. McGregor have each examined the original Piltdown remains, and the later ones described (1917) by Smith Woodward. They have all come to the conclusion that the more recently discovered lower molar tooth is much like the original type, and that it lends strong evidence in favor of Smith Woodward's conclusion that the ape-like lower jaw belongs with the man-like skull. Professor Osborn also indorses Woodward's conclusion that the ape-like canine is a lower and not an upper one, and the same view is held by Dr. Milo Hellman, whose intimate knowledge of the occlusal surfaces of teeth lends weight to his opinion.

${ }^{6}$ Pages 216 and 217 of this volume.

${ }^{7}$ Volume II of this JournaL and no. 1 of this volume.

8 No. 1 of this volume. 